\title{
Bone contusion progression from traumatic knee injury: association of rate of contusion resolution with injury severity
}

This article was published in the following Dove Press journal:

Open Access Journal of Sports Medicine

27 January 2017

Number of times this article has been viewed

\author{
Douglas R Pedersen' \\ Georges Y El-Khoury ${ }^{2}$ \\ Dan R Thedens ${ }^{3}$ \\ Mothana Saad-Eldine' \\ Phinit Phisitkul' \\ Annunziato Amendola ${ }^{4}$ \\ 'Department of Orthopaedics \\ and Rehabilitation, ${ }^{2}$ Department \\ of Radiology, University of lowa \\ Hospitals and Clinics, ${ }^{3}$ Department of \\ Electrical and Computer Engineering, \\ University of lowa, lowa City, IA, \\ ${ }^{4}$ Department of Orthopaedics and \\ Sports Medicine, Duke University \\ Medical School, Durham, NC, USA
}

Background: Bone contusions are frequently encountered in magnetic resonance imaging (MRI) evaluation of knee anterior cruciate ligament (ACL) injuries. Their role as indicators of injury severity remains unclear, primarily due to indeterminate levels of joint injury forces and to a lack of preinjury imaging.

Purpose: The purpose of this study was to 1) quantify bone contusion pathogenesis following traumatic joint injuries using fixed imaging follow-ups, and 2) assess the feasibility of using longitudinal bone contusion volumes as an indicator of knee injury severity.

Study design: Prospective sequential MRI follow-ups of a goat cohort exposed to controlled stifle trauma in vivo were compared to parallel clinical MRI follow-ups of a human ACL tear patient series.

Methods: Reproducible cartilage impact damage of various energy magnitudes was applied in a survival goat model, coupled with partial resection of anterior portions of medial menisci. Both emulate injury patterns to the knee osteochondral structures commonly encountered in human ACL injury imaging as well as instability from resultant ligament laxity. Longitudinal clinical MRI sequences portrayed stifle bone contusion evolution through 6 months after the inciting event.

Results: In the first 2 weeks, biological response variability dominated the whole-joint response with no apparent correlation to trauma severity. Control goats subjected to partial meniscectomy alone exhibited minimal bone response. Thereafter, $0.6 \mathrm{~J}$ impact bone contusions portrayed a faster rate of resolution than those induced by $1.2 \mathrm{~J}$ cartilage impacts.

Conclusion: Bone contusion sizes combined with time of persistence are likely better measures of joint injury severity than isolated bone contusion volume.

Keywords: bone contusion, contusion pathogenesis, anterior cruciate ligament, magnetic resonance imaging, knee, knee injury severity

\section{Introduction}

Posttraumatic osteoarthritis (PTOA) is an unfavorable outcome of some joint injuries, including a proportion of those associated with anterior cruciate ligament (ACL) ruptures. The advent of magnetic resonance imaging (MRI) as a diagnostic tool for joint injuries has seen the uncovering of certain features associated with ACL injuries that have not been noted in previous diagnostic modalities. These include, either collectively or individually, bone contusions, ligament disruptions, meniscal and cartilage damage, and fluid effusions. Bone contusions have become a subject of scrutiny in studies aiming to establish an association between certain features such as contusion volume and pattern with the future development of PTOA. They are the result of an impact
Correspondence: Douglas R Pedersen Research Associate Professor Orthopaedics and Rehabilitation, Orthopaedic Biomechanics Lab, 2181 Westlawn, lowa City, IA 52242, USA Tel +I 3193357533

Email doug-pedersen@uiowa.edu 
force and often involve subchondral areas of femoral as well as subjacent tibial bones of the affected knee joint. Bone contusions spark interest particularly owing to the fact that while a proportion of bone contusions associated with ACL injuries proceed to complete resolution, others are found to persist on imaging follow-ups taken a year following injury, often associated with early features of osteoarthritis (OA). Anterior subluxation of the tibia from under the femoral condyle resulting in the posterior tibial plateau impacting the femoral sulcus is often cited as a perpetuating mechanism leading to the chronicity of some ACL injury-induced bone contusions (Figure 1). This form of OA with a known inciting event provides an opportunity to study the unknown sequence of in vivo joint tissue responses that may lead to OA from a specific point in time. ${ }^{1}$

The slow progression of OA has hindered identification of explicit milestones of disease progress and injury severity. The osteoarthritis initiative (OAI), Multicenter Orthopaedic Outcomes Network (MOON) ACL Reconstruction (ACLR), the SEKOIA Study, and the Multicenter Osteoarthritis Study (MOST) offer insight into the broad problem of knee injury and OA. ${ }^{1-5}$ Typically, human patients are only imaged after the injury for diagnosis (1-14 days) and during a subsequent presurgery workup ( $\sim-4$ weeks). Limited and irregular timing of clinical MRI of patients has impeded the definition of early PTOA onset. A prospective longitudinal study of ACL rupture patients evaluated quantitative MRI sequences (delayed gadolinium MRI of cartilage [dGEMRIC], T1 in the rotating reference frame [T1 $\rho]$, and T2 multitime series maps) for cartilage condition and composition. ${ }^{6}$ The early time frame after injury during which osteochondral biopsies were harvested demonstrated T1 $\rho$ 's effectiveness as a clinical biomarker prior to irreversible proteoglycan (PG) loss and
OA onset. ${ }^{7}$ These patients' clinical MRI records provide the human context for this report on bone contusion presence after traumatic knee injury. Bone bruises are a prominent visual feature that lend themselves to association of contusion volume with injury magnitude. However, without a direct measure of injury, separation from biological variability is not possible.

Animal models are an approach to overcome the limitations of human participation in studies of the early pathogenesis of PTOA..$^{8-10}$ These preclinical models permit isolation of traumatic injury features but must include means of creating realistic joint injury simulating in vivo clinical joint trauma. ${ }^{11,12}$ We have created reproducible cartilage impact damage with a handheld pneumatic impactor ${ }^{13}$ through an anterior partial meniscectomy (APM) ${ }^{14}$ in a survival goat model of PTOA. Longitudinal clinical MRI sequences revealed bone contusion progression from preinjury normal through 6 months after traumatic injury in the goat stifle model. We compared these to parallel clinical MRI followups of a human ACL tear patient series.

\section{Methods}

Reproducible cartilage impact damage was applied in a survival goat model of PTOA. An APM presents a relatively simple, reproducible method to expose the femoral condyle weight-bearing area and to surgically create abnormal contact mechanics without dramatically destabilizing the joint. ${ }^{14} \mathrm{We}$ developed and calibrated an easy-to-use handheld pneumatic impactor to create reproducible cartilage damage. ${ }^{13}$

Twenty goats were included in this study, which was approved by the University of Iowa Institutional Animal Care and Use Committee (IACUC 5061417). Animal Welfare Act (AWA) and Office of Lab Animal Welfare (OLAW)
A

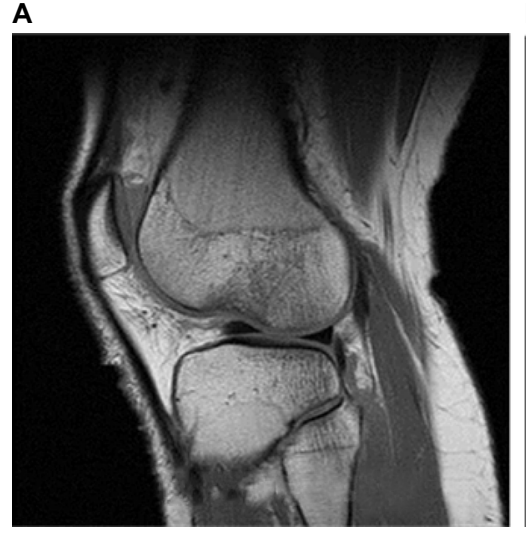

B

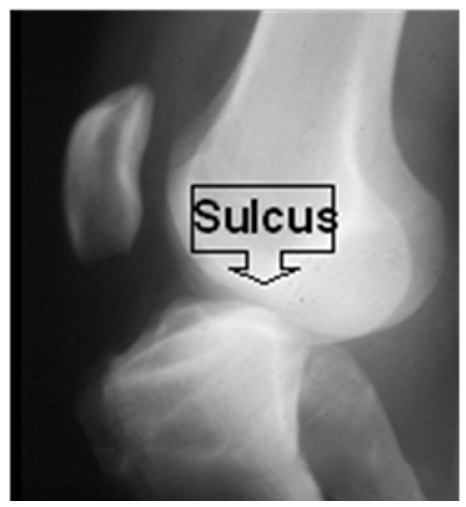

C

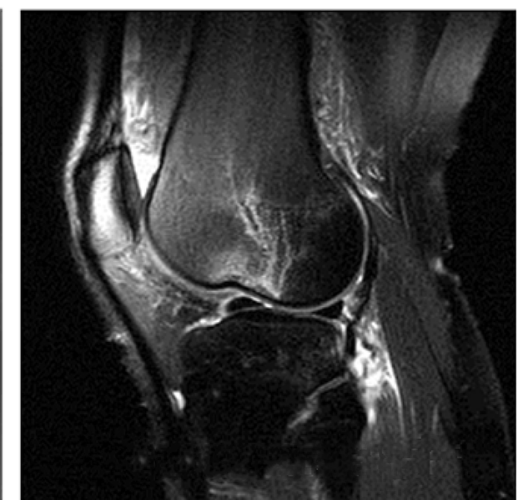

Figure I Diagnostic MRI sequences provide anatomic visualization of the whole joint (proton density) and impressions of fluid effusion and bone trauma (T2 fat-saturated MRI).

Notes: (A) Sagittal proton density MRI. (B) Prereduction radiograph. (C) Sagittal T2 fat-saturated MRI.

Abbreviation: MRI, magnetic resonance imaging. 
guidelines were followed. The knee injury procedure was performed through an anterior arthrotomy over the medial condyle. A $5 \mathrm{~mm}$ wedge was excised from the anterior horn of the medial meniscus to induce a limited joint instability in all 20 left stifles. This opening provided an unobstructed view of the cartilage surfaces of the flexed knee. The loadbearing cartilage on eight medial condyles was impacted with a single impulse of $0.6 \mathrm{~J}$ of energy from a specially designed handheld pneumatic impactor with a flat circular $6 \mathrm{~mm}$ contact surface. A more severe cartilage contusion was induced by a $1.2 \mathrm{~J}$ impact to six other goats' stifles. The remaining six stifles were not impacted after the APM. As in the human ACL cohort, common clinical knee diagnostic and morphological MRI sequences were acquired on a $3 \mathrm{~T}$ Siemens TIM Trio platform on each of the survival series goat-patients to reveal whole-joint tissue responses. The longitudinal in vivo goat study time points are preoperative and $3,7,14,28,56,112$, and 168 days postoperative.

The prospective ACL study was approved by the University's Human Subjects Research Review Board (IRB ID \# 200702733). Written informed consent was obtained before enrollment, and testing after the nature of the study had been explained. Nine patients (average age at injury of 23.5 years) had 28 MRI sessions; six diagnostic protocols at injury, eight ACLR preoperative work-ups, and 13 postoperative MRI sessions. T2-weighted fast spin echo MR images are used primarily to look at bone marrow contusion, cartilage surfaces, and synovial fluid. The bone contusion appears as an intense white area subjacent to the impacted (black) subchondral bone (Figure 2). The bone injuries were segmented on serial sagittal MRI slices using ImageJ (http:// imagej.nih.gov/ij/), and the area in each slice was recorded as the number of included pixels. Contusion volumes were calculated as the number of voxels $\times$ the voxel volume of $1.13 \mathrm{~mm}^{3}$ (volume $=$ in-plane pixel resolution $\times$ slice thickness). The less distinct background fluid effusion in the bone marrow was not included as it appears as a typical transient tissue response in these serial images.

The trends of the three levels of goat stifle injuries were compared to those of the human cohort.

\section{Results}

A sagittal mid-contusion $\mathrm{T} 2$ fat-saturated image from each of the longitudinal MRI sessions visually documents the progression of bone response to a known impact injury magnitude to that goat's medial condyle (Figure 3). Only one of the six goat stifles with an anterior meniscectomy alone exhibited any bone response $\left(130,56\right.$, and $20 \mathrm{~mm}^{3}$ at 3, 7, and 14 days postoperatively). Longitudinal bone contusion volumes measured at the eight designated time points are reported for the eight goats with an APM plus $0.6 \mathrm{~J}$ impact injuries (Table 1) and for the six goats with an APM plus $1.2 \mathrm{~J}$ impact injuries (Table 2). Group averages at each time point for these two cohorts were also calculated (Table 3).

In the first 2 weeks, biological response variability dominated the whole-joint response. Femoral contusion volumes for each of the ACL patient's MRI sessions are plotted versus their follow-up times (Figure 4). Biological variability also dominated the first 2 weeks' whole-joint response in the survival goat model of PTOA (Figure 5). Thereafter, the bone contusions began to resolve faster in the $0.6 \mathrm{~J}$ impaction knees than in those with a $1.2 \mathrm{~J}$ cartilage impact. APM alone exhibited minimal bone response.

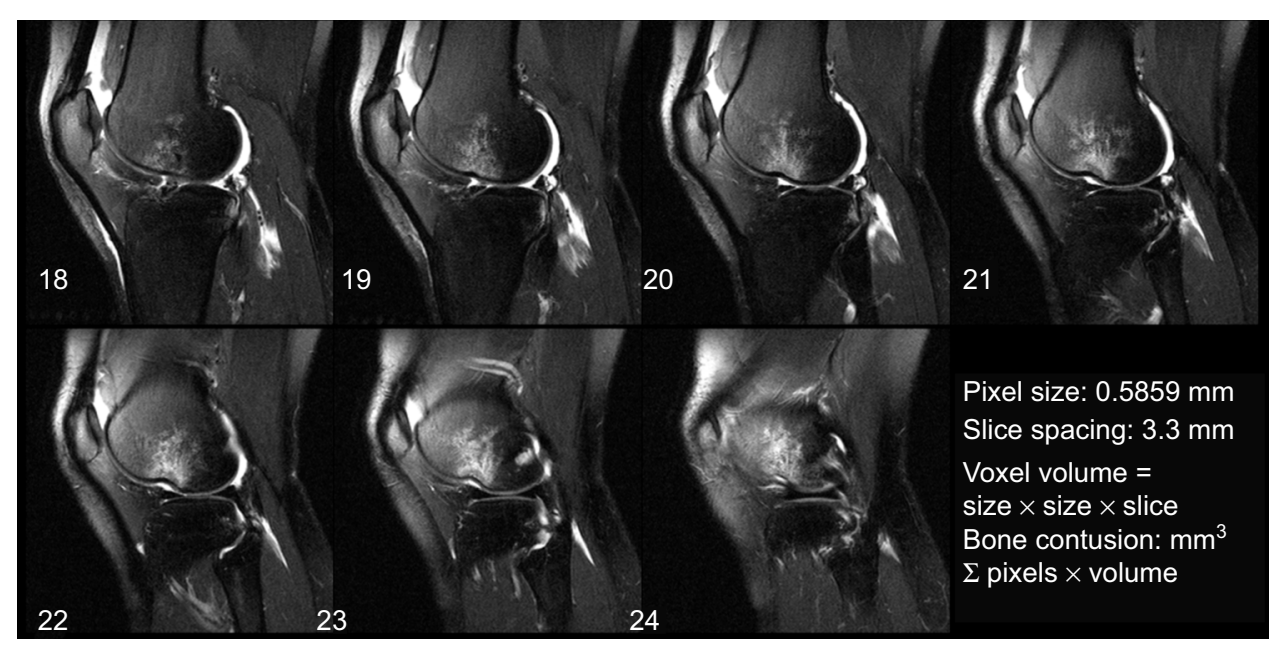

Figure 2 Serial T2 fat-saturated MRI images of a young patient's knee after an ACL rupture injury while playing volleyball.

Notes: The bone contusion spreads through multiple sagittal image slices (18-24). This ACL patient's contusion volume was measured as I6,055 mm ${ }^{3}$ during a same day as injury diagnostic MRI. The bruise resolved to $24,112,577$, and $144 \mathrm{~mm}^{3}$ at 22, 149, and 280 days postinjury, respectively.

Abbreviations: $A C L$, anterior cruciate ligament; MRI, magnetic resonance imaging. 


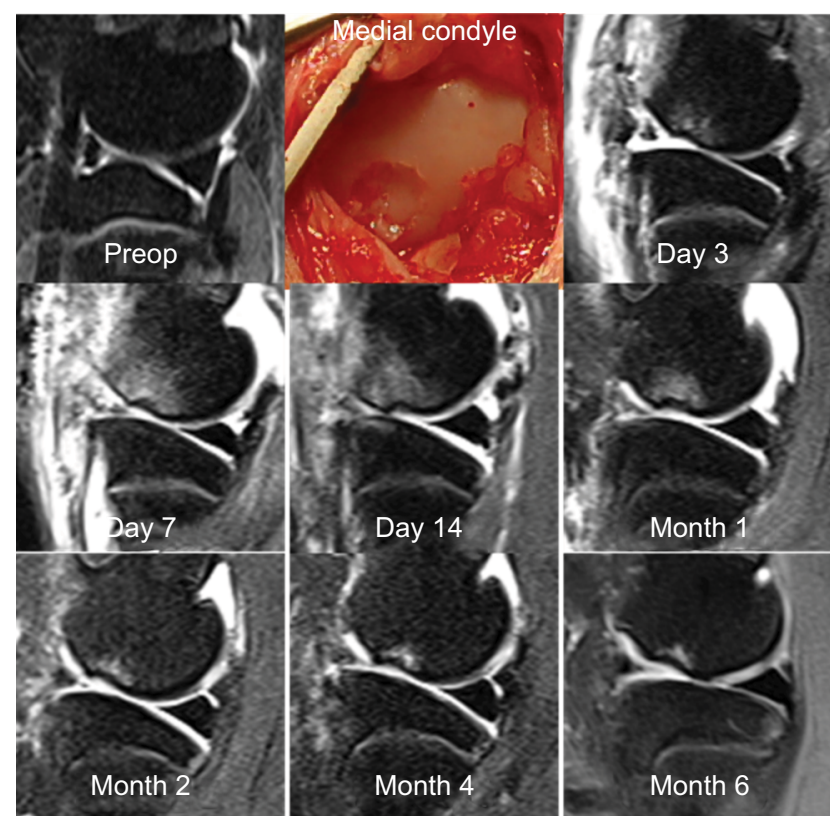

Figure 3 The left stifle of goat 50007 was subjected to a $1.2 \mathrm{~J}$ impact on the weightbearing femoral condyle surface.

Notes: The circular impact is visible directly behind the anterior meniscus resection. Mid-contusion T2 fat-saturated MRI slices are displayed at each of the time points to document the injury progression.

Abbreviations: preop, preoperatively; MRI, magnetic resonance imaging.

\section{Discussion}

ACL tear-involving knee injuries are frequently encountered in clinical practice. Estimates of ACLR surgeries performed in the US annually range between 60,000 and $175,0000^{3,15}$ This figure does not accurately reflect the true annual burden of ACL injuries as it does not include the proportion of ACL tear patients undergoing arthroscopic ACL debridement procedures or being managed conservatively. In fact, a study conducted over a period of 3 years at a tertiary care center in a busy urban setting has revealed the ratio of incidence of ACLRs to ACL injury diagnosis to be $22 \%{ }^{16}$

Knee injuries involving ACL tears are a source of significant morbidity and disability owing to a multitude of factors. They entail a period of recovery often spanning a protracted amount of time and commonly involve frequent outpatient visits, pain management, tedious rehabilitation, and invasive diagnostic and management procedures. ACL injuries also show preponderance in populations enrolled in physically demanding careers such as contact sports. An estimate shows risk of ACL injury among sports such as football, soccer, and skiing, labeled high-risk sports, to be 10 times that in other activities. ${ }^{12,17}$ Data

Table I Longitudinal bone contusion progression after anterior partial meniscectomy plus $0.6 \mathrm{~J}$ impact injuries

\begin{tabular}{|c|c|c|c|c|c|c|c|c|c|c|c|c|c|c|c|c|}
\hline \multirow{2}{*}{$\begin{array}{l}\text { MRI } \\
\text { event }\end{array}$} & \multicolumn{2}{|c|}{50001} & \multicolumn{2}{|c|}{50004} & \multicolumn{2}{|l|}{50003} & \multicolumn{2}{|c|}{50008} & \multicolumn{2}{|l|}{50009} & \multicolumn{2}{|l|}{50010} & \multicolumn{2}{|l|}{50019} & \multicolumn{2}{|l|}{50020} \\
\hline & Days & $\begin{array}{l}\text { BMEL } \\
\left(\mathrm{mm}^{3}\right)\end{array}$ & Days & $\begin{array}{l}\text { BMEL } \\
\left(\mathrm{mm}^{3}\right)\end{array}$ & Days & $\begin{array}{l}\text { BMEL } \\
\left(\mathrm{mm}^{3}\right)\end{array}$ & Days & $\begin{array}{l}\text { BMEL } \\
\left(\mathrm{mm}^{3}\right)\end{array}$ & Days & $\begin{array}{l}\text { BMEL } \\
\left(\mathrm{mm}^{3}\right)\end{array}$ & Days & $\begin{array}{l}\text { BMEL } \\
\left(\mathrm{mm}^{3}\right)\end{array}$ & Days & $\begin{array}{l}\text { BMEL } \\
\left(\mathrm{mm}^{3}\right)\end{array}$ & Days & $\begin{array}{l}\text { BMEL } \\
\left(\mathrm{mm}^{3}\right)\end{array}$ \\
\hline Preop & -13 & & -13 & & -39 & & -39 & & -28 & & -28 & & -40 & & -40 & \\
\hline Surgery & 0 & & 0 & & 0 & & 0 & & 0 & & 0 & & 0 & & 0 & \\
\hline Day 3 & 3 & 215 & 3 & 54 & 3 & 78 & 3 & $13 \mid$ & 3 & 95 & 3 & 70 & 3 & 20 & 3 & 307 \\
\hline Week I & 7 & 715 & 7 & 514 & 7 & 536 & 7 & 66 & 7 & 499 & 7 & 252 & 7 & 197 & 7 & 466 \\
\hline Week 2 & 13 & 618 & 13 & 506 & 14 & 411 & 14 & 43 & 15 & 243 & 15 & 276 & 14 & 78 & 14 & 252 \\
\hline I month & 27 & 262 & 27 & 252 & 28 & 277 & 28 & 19 & 27 & 72 & 27 & 106 & 28 & 0 & 28 & 110 \\
\hline 2 months & 55 & 214 & 55 & 234 & 56 & 85 & 56 & 5 & 55 & 175 & 55 & 90 & 55 & 0 & 55 & 95 \\
\hline 4 months & 111 & 192 & 111 & 111 & 111 & 68 & 111 & 27 & 112 & 69 & 112 & 0 & 76 & 0 & 128 & 48 \\
\hline 6 months & 168 & 80 & 168 & 21 & 168 & 39 & 168 & 0 & 168 & 29 & 168 & 0 & Lung $P$ & arasite & 168 & 21 \\
\hline
\end{tabular}

Note: 5000 I to 50020 relate to the individual goat IDs.

Abbreviations: BMEL, bone marrow edema lesions; MRI, magnetic resonance imaging; preop, preoperatively.

Table 2 Longitudinal bone contusion progression after anterior partial meniscectomy plus I.2 J impact injuries

\begin{tabular}{|c|c|c|c|c|c|c|c|c|c|c|c|c|}
\hline \multirow[t]{2}{*}{ MRI event } & \multicolumn{2}{|l|}{50002} & \multicolumn{2}{|l|}{50007} & \multicolumn{2}{|l|}{50013} & \multicolumn{2}{|l|}{50014} & \multicolumn{2}{|l|}{50011} & \multicolumn{2}{|c|}{50012} \\
\hline & Days & $\begin{array}{l}\text { BMEL } \\
\left(\mathrm{mm}^{3}\right)\end{array}$ & Days & $\begin{array}{l}\text { BMEL } \\
\left(\mathrm{mm}^{3}\right)\end{array}$ & Days & $\begin{array}{l}\text { BMEL } \\
\left(\mathrm{mm}^{3}\right)\end{array}$ & Days & $\begin{array}{l}\text { BMEL } \\
\left(\mathrm{mm}^{3}\right)\end{array}$ & Days & $\begin{array}{l}\text { BMEL } \\
\left(\mathrm{mm}^{3}\right)\end{array}$ & Days & $\begin{array}{l}\text { BMEL } \\
\left(\mathrm{mm}^{3}\right)\end{array}$ \\
\hline Preop & -29 & & -29 & & -13 & & -13 & & -28 & & -28 & \\
\hline Surgery & 0 & & 0 & & 0 & & 0 & & 0 & & 0 & \\
\hline Day 3 & 3 & 47 & 3 & 416 & 3 & 80 & 3 & 105 & 3 & 0 & 3 & 387 \\
\hline Week I & 7 & 206 & 7 & 924 & 7 & 113 & 7 & 59 & 7 & 633 & 7 & 462 \\
\hline Week 2 & 15 & 156 & 15 & 862 & 13 & 95 & 13 & 145 & 15 & 593 & 15 & 552 \\
\hline I month & 27 & 166 & 27 & 311 & 27 & 15 & 27 & 430 & 27 & 154 & 27 & 371 \\
\hline 2 months & 55 & 135 & 55 & 284 & 55 & 144 & 55 & 249 & 55 & 0 & 55 & 175 \\
\hline 4 months & 111 & 37 & 111 & 209 & 112 & 86 & 112 & 180 & 112 & 0 & 112 & 149 \\
\hline 6 months & 157 & $S$ & 182 & 45 & 168 & 57 & 168 & 119 & 169 & 32 & 169 & 78 \\
\hline
\end{tabular}

Note: 50002 to 50014 relate to the individual goat IDs.

Abbreviations: BMEL, bone marrow edema lesions; MRI, magnetic resonance imaging; preop, preoperatively. 
Table 3 Group averages at each time used for power statistics

\begin{tabular}{llllllll}
\hline MRI event & \multicolumn{3}{c}{ APM plus 0.6 J impact } & & \multicolumn{3}{c}{ APM plus I.2 J impact } \\
\cline { 2 - 4 } \cline { 7 - 8 } & Count & Mean & SD & & Count & Mean & SD \\
\hline Day 3 & 8 & 121 & 95 & 6 & 172 & 181 \\
Week I & 8 & 405 & 213 & 6 & 399 & 337 \\
Week 2 & 8 & 303 & 199 & 6 & 400 & 313 \\
I month & 8 & 137 & 111 & 6 & 241 & 156 \\
2 months & 8 & 112 & 88 & 6 & 165 & 100 \\
4 months & 8 & 64 & 64 & 6 & 110 & 83 \\
6 months & 7 & 27 & 27 & 6 & 56 & 38 \\
\hline
\end{tabular}

Abbreviations: MRI, magnetic resonance imaging; APM, anterior partial meniscectomy; SD, standard deviation. from the National Football League estimate the proportion of participants who have sustained ACL injuries to be $8 \%,{ }^{17} \sim 35 \%$ of the total number of injuries. ${ }^{18}$ Perhaps one of the main reasons ACL injuries receive attention is their association with earlyonset $\mathrm{OA}$, a potentially highly morbid condition particularly in light of the young mean age of ACL injury patients. PTOA is an outcome of some, but not all ACL injuries, a phenomenon that has inspired research aimed to identifying features of ACL injury that predict future onset of $\mathrm{OA}$ and subsequently devise interventions that would avert this adverse outcome.

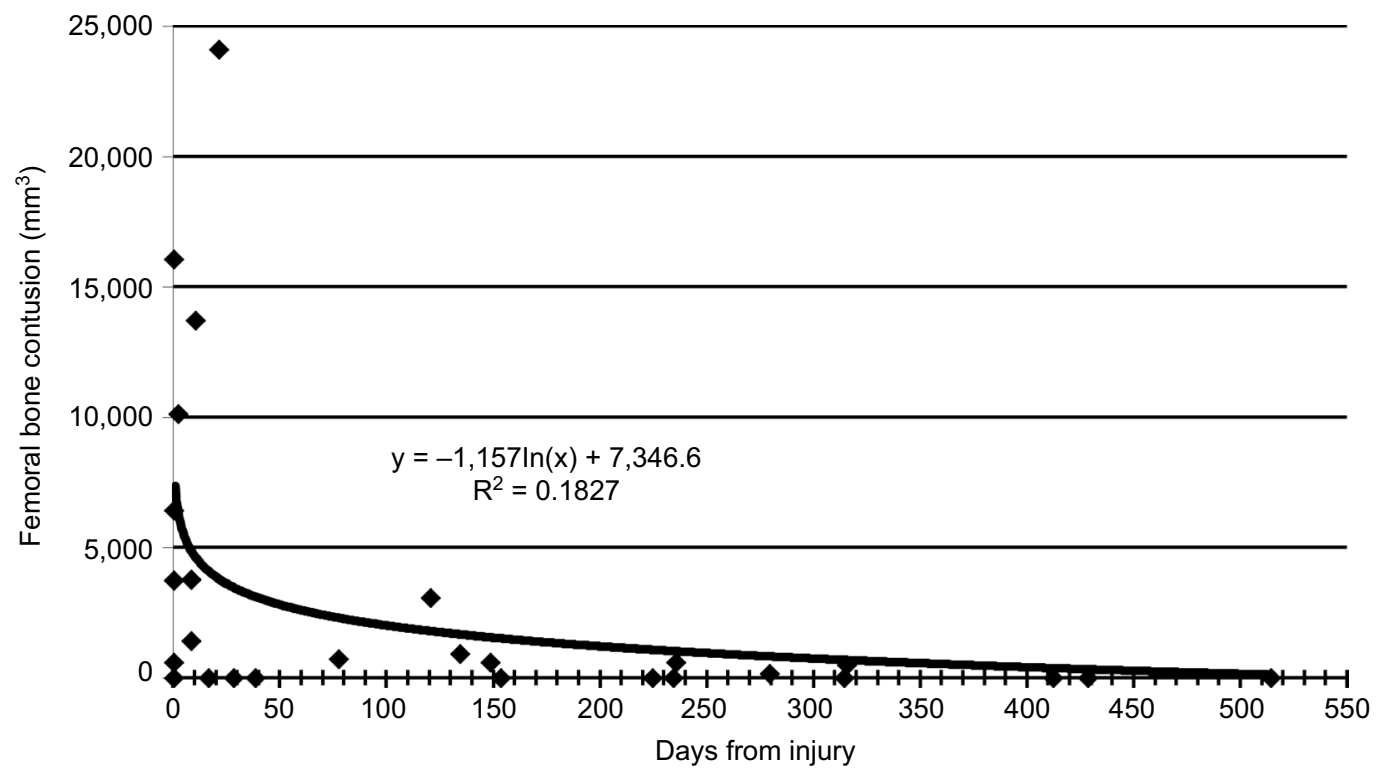

Figure 4 Human ACLR patient bone contusion volumes versus days from injury.

Notes: Differing bone contusion resolution times are recorded (zero volumes) along the cohort trend line. High variability of initial bone contusion sizes mirrors the goat stifle results. But without measures of the injury magnitudes, it is difficult to catalog or predict an individual patient's path to recovery.

Abbreviation: ACLR, anterior cruciate ligament reconstruction.

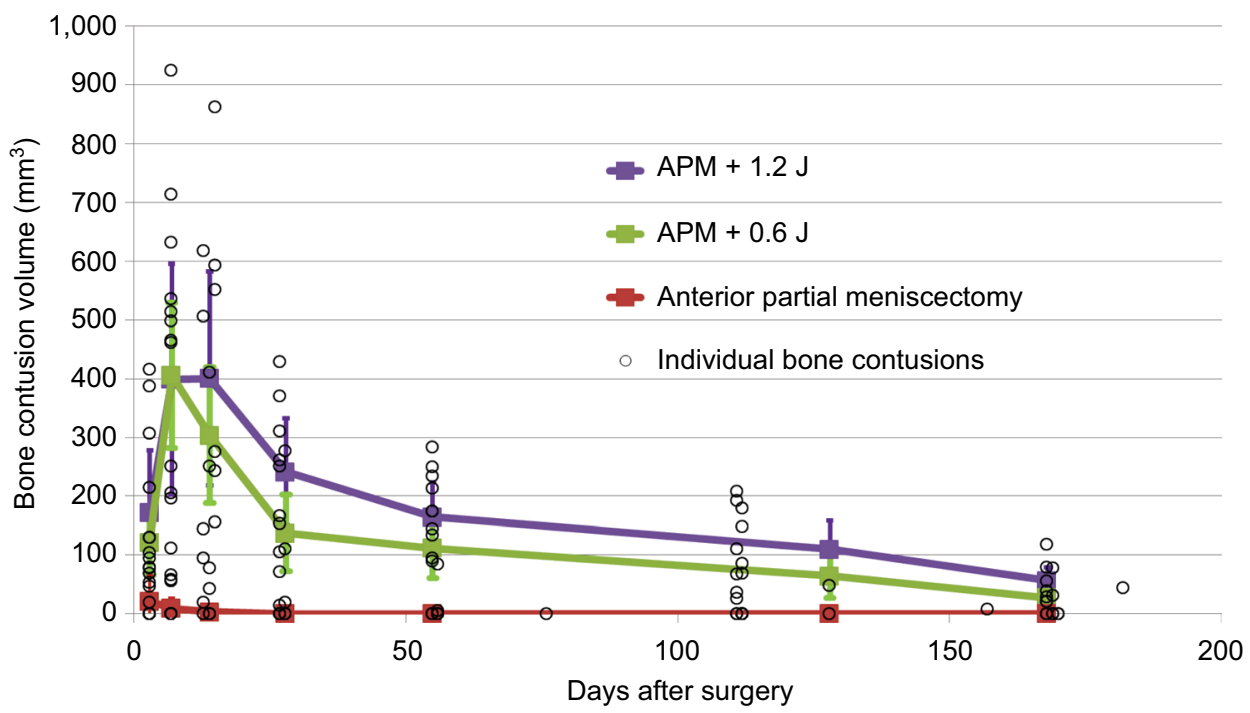

Figure 5 Goat contusion volumes are plotted individually at all times.

Notes: The three grouped averages are graphed with standard deviation to exhibit trends in bone contusion volumes with respect to well-characterized injury insults. Contusion expansion appears to peak at 7 days and to persist longer in the higher impact cases.

Abbreviation: APM, anterior partial meniscectomy. 
In addition to facilitating early, noninvasive ACL injury diagnosis, the advent of MRI in clinical practice has uncovered certain features associated with ACL tears that have not been identified using prior imaging modalities. Most notable of these are bone contusions or bruises. These are areas of diminished signal intensity on proton density or T1-weighted images and increased signal density on T2-weighted images. They are believed to be areas of edema, hemorrhage, and infarction resultant from trabecular microfractures. ${ }^{19,20}$ An estimated $80 \%$ of patients with ACL rupture show concomitant bone bruising on MRI. ${ }^{21-23}$ Bone bruising is also noted in other ligament injuries ${ }^{24,25}$ as well as in knee injuries where ligaments remain intact. ${ }^{26}$ They are believed to be a result of direct trauma to the bone, shear stress from the compression of adjacent bone surfaces, or traction forces from ligament avulsions.

The role of bone contusions as indicators of injury severity is unknown. This is also true for the association of bone bruising in general or specific patterns of bone bruising with the future development of PTOA. While some researchers conclude that bone contusions in general proceed to full resolution with time, ${ }^{22,25}$ others report persistence of at least a proportion of bone contusions a year following the initial injury in addition to the appearance of sequelae in the form of degenerative changes as early as 6 months postinjury. ${ }^{23,27}$ This was originally attributed to dysfunctional bone kinematics resulting from ligament insufficiency as well as meniscal compromise commonly associated with ACL injury that have acted as a perpetuating mechanism of the original insult. However, data showing development of PTOA 5-10 years from injury onset, even in ACLR patients and those with in tact menisci who are sometimes even at a higher rate than nonreconstructed ACL injury patients, indicate the dysfunctional kinematics explanation cannot be generalized onto all situations. ${ }^{28-30}$ Furthermore, it indicates that the magnitude and pattern of the original bone and cartilage injuries have a sizeable role in predisposing for PTOA.

Conflicting findings and recommendations yielded from studies addressing ACL injury patients stem from comparing results from a wide range of $\mathrm{MRI}$ platforms, and an inherent difficulty in applying research designs that would control for potentially confounding variables to the one under investigation. ACL injury investigations also face difficulties in attaining such necessary details as time between injury and receiving medical attention, mechanism and magnitude of injury, demographics, return to preinjury activity, reinjury, and complications that may arise in the short and in the long run. Patient studies generally lack both preinjury and sufficient early regular postinjury imaging sessions to document whole-joint tissue responses to traumatic injury.

Our current study design attempts to address issues commonly encountered in ACL injury related investigations. Through simulation of knee injury in a survival goat model, we have overcome difficulties in attaining relevant details due to poor documentation or loss to follow-up. Furthermore, we have standardized our goat models through surgically induced joint instability in addition to devising and validating tools to induce controlled traumatic injuries to the bone/ cartilage interface. These procedures have been applied to three groups of goats, and followed in time with clinically available MRI sequences.

Only one of six nonimpacted APM instability stifles demonstrated a distinct focal intensity increase in bone marrow response in the reported T2-weighted fast spin echo images. This was short lived in the typical acute time period of injury (3 days) to surgery (2-3 weeks) seen in the human ACL rupture cohort. The biological response of the bone to two distinct controlled cartilage impactions is evinced in the average and individual goat PTOA models. If a joint exhibits a $200 \mathrm{~mm}^{3}$ bone contusion at 4 weeks, it is in the gray zone between applied impact energies (Figure 5). However, if that same contusion persists at 8 weeks, it is more likely to involve bone remodeling toward sclerotic or increased porosity subchondral support and likely accelerated cartilage erosion and earlier OA onset. A power statistic of these two impact groups suggests that two or more animals in each would separate the later 4- and 6-month trends. Increasing numbers at each previous time point would be required to overcome the acute biological variability, presenting the primary limitation of longitudinal in vivo animal studies. The study did, however, isolate the role of impact injury magnitude on bone contusion pathogenesis.

\section{Conclusion}

This longitudinal series of bone responses provides a first look at PTOA pathogenesis in an in vivo animal model and a means to better address radiologic interpretations of human MRI injury images to physical phenomena. Bone contusion sizes combined with time of persistence are likely better measures of joint injury severity than isolated bone contusion volume.

\section{Acknowledgment}

This work was funded by NIH/NIAMS grant P50 AR055533 and the American Orthopaedic Society for Sports Medicine.

\section{Disclosure}

The authors report no conflicts of interest in this work. 


\section{References}

1. Lynch JA, Roemer FW, Nevitt MC, et al. Comparison of BLOKS and WORMS scoring systems part I. Cross sectional comparison of methods to assess cartilage morphology, meniscal damage and bone marrow lesions on knee MRI: data from the osteoarthritis initiative. Osteoarthritis Cartilage. 2010;18(11):1393-1401.

2. Spindler KP, Wright RW. Clinical practice. Anterior cruciate ligament tear. N Engl J Med. 2008;359(20):2135-2142.

3. Edwards MH, Parsons C, Bruyere O, et al. High Kellgren-Lawrence grade and bone marrow lesions predict worsening rates of radiographic joint space narrowing; The SEKOIA Study. J Rheumatol. 2016;43(3): 657-665.

4. Hettrich CM, Dunn WR, Reinke EK, Group M, Spindler KP. The rate of subsequent surgery and predictors after anterior cruciate ligament reconstruction: two- and 6-year follow-up results from a multicenter cohort. Am J Sports Med. 2013;41(7):1534-1540.

5. Ratzlaff C, Guermazi A, Collins J, et al. A rapid, novel method of volumetric assessment of MRI-detected subchondral bone marrow lesions in knee osteoarthritis. Osteoarthritis Cartilage. 2013;21(6):806-814.

6. Klocke NF, Amendola A, Thedens DR, et al. Comparison of T1rho, dGEMRIC, and quantitative T2 MRI in preoperative ACL rupture patients. Acad Radiol. 2013;20(1):99-107.

7. Pedersen DR, Martin JA, Thedens DR, et al. Imaging biopsy composition at ACL reconstruction. Orthop Res Rev. 2013;5:35-41.

8. Aigner T, Cook JL, Gerwin N, et al. Histopathology atlas of animal model systems - overview of guiding principles. Osteoarthritis Cartilage. 2010;18(suppl 3):S2-S6.

9. Berenbaum F. The OARSI histopathology initiative - the tasks and limitations. Osteoarthritis Cartilage. 2010;18(suppl 3):S1.

10. Poole R, Blake S, Buschmann M, et al. Recommendations for the use of preclinical models in the study and treatment of osteoarthritis. Osteoarthritis Cartilage. 2010;18(suppl 3):S10-S16.

11. DeHaven KE, Lintner DM. Athletic injuries: comparison by age, sport, and gender. Am J Sports Med. 1986;14(3):218-224.

12. Warme WJ, Feagin JA Jr, King P, Lambert KL, Cunningham RR. Ski injury statistics, 1982 to 1993, Jackson Hole Ski Resort. Am J Sports Med. 1995;23(5):597-600.

13. Pedersen DR, Rudert MJ, Heckelsmiller DJ, Baer TE, Fredericks DC, Goetz JE. A handheld device for creating cartilage blunt impact injuries in survival animal models. Osteoarthritis Cartilage. 2016;24:S403.

14. Pedersen DR, Heckelsmiller DJ, Rudert MJ, Goetz JE. An anterior partial meniscectomy changes joint contact mechanics in a large quadrupedal animal model of osteoarthritis. Osteoarthritis Cartilage. 2016;24:S393-S394.

15. Frank CB, Jackson DW. The science of reconstruction of the anterior cruciate ligament. J Bone Joint Surg Am. 1997;79(10):1556-1576.
16. Collins JE, Katz JN, Donnell-Fink LA, Martin SD, Losina E. Cumulative incidence of ACL reconstruction after ACL injury in adults: role of age, sex, and race. Am J Sports Med. 2013;41(3):544-549.

17. Brophy RH, Chehab EL, Barnes RP, Lyman S, Rodeo SA, Warren RF. Predictive value of orthopedic evaluation and injury history at the NFL combine. Med Sci Sports Exerc. 2008;40(8):1368-1372.

18. Bradley J, Honkamp NJ, Jost P, West R, Norwig J, Kaplan LD. Incidence and variance of knee injuries in elite college football players. $A m J$ Orthop (Belle Mead NJ). 2008;37(6):310-314.

19. Kapelov SR, Teresi LM, Bradley WG, et al. Bone contusions of the knee: increased lesion detection with fast spin-echo MR imaging with spectroscopic fat saturation. Radiology. 1993;189(3):901-904.

20. Steiner RM, Mitchell DG, Rao VM, Schweitzer ME. Magnetic resonance imaging of diffuse bone marrow disease. Radiol Clin North Am. 1993;31(2):383-409.

21. Engebretsen L, Arendt E, Fritts HM. Osteochondral lesions and cruciate ligament injuries. MRI in 18 knees. Acta Orthop Scand. 1993;64(4): 434-436.

22. Graf BK, Cook DA, De Smet AA, Keene JS. "Bone bruises" on magnetic resonance imaging evaluation of anterior cruciate ligament injuries. $A m$ J Sports Med. 1993;21(2):220-223.

23. Vellet AD, Marks PH, Fowler PJ, Munro TG. Occult posttraumatic osteochondral lesions of the knee: prevalence, classification, and shortterm sequelae evaluated with MR imaging. Radiology. 1991;178(1): 271-276.

24. Mair SD, Schlegel TF, Gill TJ, Hawkins RJ, Steadman JR. Incidence and location of bone bruises after acute posterior cruciate ligament injury. Am J Sports Med. 2004;32(7):1681-1687.

25. Miller MD, Osborne JR, Gordon WT, Hinkin DT, Brinker MR. The natural history of bone bruises. A prospective study of magnetic resonance imaging-detected trabecular microfractures in patients with isolated medial collateral ligament injuries. Am J Sports Med. 1998;26(1):15-19.

26. Wright RW, Phaneuf MA, Limbird TJ, Spindler KP. Clinical outcome of isolated subcortical trabecular fractures (bone bruise) detected on magnetic resonance imaging in knees. Am J Sports Med. 2000;28(5):663-667.

27. Davies NH, Niall D, King LJ, Lavelle J, Healy JC. Magnetic resonance imaging of bone bruising in the acutely injured knee - short-term outcome. Clin Radiol. 2004;59(5):439-445.

28. Daniel DM, Stone ML, Dobson BE, Fithian DC, Rossman DJ, Kaufman KR. Fate of the ACL-injured patient. A prospective outcome study. Am J Sports Med. 1994;22(5):632-644.

29. Fithian DC, Paxton EW, Stone ML, et al. Prospective trial of a treatment algorithm for the management of the anterior cruciate ligament-injured knee. Am J Sports Med. 2005;33(3):335-346.

30. Myklebust G, Bahr R. Return to play guidelines after anterior cruciate ligament surgery. Br J Sports Med. 2005;39(3):127-131.
Open Access Journal of Sports Medicine

\section{Publish your work in this journal}

The Open Access Journal of Sports Medicine is an international, peer-reviewed, open access journal publishing original research, reports, reviews and commentaries on all areas of sports medicine. The journal is included on PubMed. The manuscript management system is completely online and includes a very quick and fair

\section{Dovepress}

peer-review system. Visit http://www.dovepress.com/testimonials.php to read real quotes from published authors. 